\title{
Waste Cellulose from Tetra Pak Packages as Reinforcement of Cement Concrete
}

\author{
Gonzalo Martínez-Barrera, ${ }^{1}$ Carlos E. Barrera-Díaz, ${ }^{2}$ \\ Erick Cuevas-Yañez, ${ }^{2}$ Víctor Varela-Guerrero, ${ }^{2}$ Enrique Vigueras-Santiago, ${ }^{1}$ \\ Liliana Ávila-Córdoba, ${ }^{2}$ and Miguel Martínez-López ${ }^{1}$ \\ ${ }^{1}$ Laboratorio de Investigación y Desarrollo de Materiales Avanzados (LIDMA), Facultad de Química, \\ Universidad Autónoma del Estado de México, $\mathrm{km} 12$ de la Carretera Toluca-Atlacomulco, 50200 San Cayetano, Mexico \\ ${ }^{2}$ Centro Conjunto de Investigación en Química Sustentable, Universidad Autónoma del Estado de México-Universidad Nacional \\ Autónoma de México (UAEM-UNAM), Carretera Toluca-Atlacomulco km 14.5, 50200 San Cayetano, Mexico
}

Correspondence should be addressed to Gonzalo Martínez-Barrera; gonzomartinez02@yahoo.com.mx

Received 8 September 2014; Revised 19 December 2014; Accepted 8 January 2015

Academic Editor: Hao Wang

Copyright ( 2015 Gonzalo Martínez-Barrera et al. This is an open access article distributed under the Creative Commons Attribution License, which permits unrestricted use, distribution, and reproduction in any medium, provided the original work is properly cited.

\begin{abstract}
The development of the packaging industry has promoted indiscriminately the use of disposable packing as Tetra Pak, which after a very short useful life turns into garbage, helping to spoil the environment. One of the known processes that can be used for achievement of the compatibility between waste materials and the environment is the gamma radiation, which had proved to be a good tool for modification of physicochemical properties of materials. The aim of this work is to study the effects of waste cellulose from Tetra Pak packing and gamma radiation on the mechanical properties of cement concrete. Concrete specimens were elaborated with waste cellulose at concentrations of 3,5, and $7 \mathrm{wt} \%$ and irradiated at 200, 250, and $300 \mathrm{kGy}$ of gamma dose. The results show highest improvement on the mechanical properties for concrete with $3 \mathrm{wt} \%$ of waste cellulose and irradiated at $300 \mathrm{kGy}$; such improvements were related with the surface morphology of fracture zones of cement concrete observed by SEM microscopy.
\end{abstract}

\section{Introduction}

Due to the increment of awareness on environment, the use of waste materials is an attractive area of opportunity. Solid wastes are classified by their chemical nature as organic and inorganic; recovery of them has been under study for a long time. Use of waste in building materials, road construction, and pavement are beneficial because it reduces environmental pollution and solves the waste disposal problems [1, 2]. Such waste materials should show an effective recycling or reuse [3]. Several improvements have been reported for incorporating waste of recycled polymers, for example, in the case of asphalt pavement or in road performances [4-6].

Among waste materials are those containing cellulose as Tetra Pak packages; such packing is made up of three raw materials: paper (about 75\%), low density polyethylene (about 20\%), and aluminum (about 5\%). Aseptic packages are recycled through a simple, well-established process called hydropulping. In this process, the cellulosic fibers are separated from thin layers of polyethylene and aluminum. Early study on Tetra Pak garbage showed recovery of their components, being cardboard $63 \mathrm{wt} \%$, polyethylene $30 \mathrm{wt} \%$, and aluminum $7 \mathrm{wt} \%$ [7].

Degradation of cellulose or lingocellulosic materials produced huge number of water soluble or insoluble oxygenated compounds. The water content of aqueous phases is high, and it contains some valuable chemicals; one of them is phenolic compounds. It is convenient to mention that high-quality cellulosic fibers are used in the production of paper products such as tissue and paper towels and fine writing paper.

Some investigations are concerned with the use of cellulosic materials as fillers in composite materials. Most of the waste from the paper industry is known as paper sludge (PS) which is burnt and becomes PS ash. This is used as a soil improvement material and cement raw material. PS ash increased the strength of extremely stiff concrete; moreover, 
it has high water absorption [8,9]. Different composite materials have been produced by incorporating cellulosic materials for improvement of mechanical properties: (a) bending behavior is improved by incorporating cellulose fibers from waste paper; (b) toughness and tensile behavior of thin-sheet cement products are improved by adding fibers of recycled waste paper; $(\mathrm{c})$ shore hardness $(\mathrm{SH})$ values are increased as the resin concentration increases in composites elaborated with Tetra Pak and resin materials; and (d) maximum of strengthening is achieved for cement matrixes when adding plant-fibers and man-made cellulose fibers (from 8 to $10 \mathrm{wt} \%)$; the costs are reduced with this substitution $[4,5,9$, $10]$.

The mechanical improvements when using cellulose fibers are due mainly to their mechanical properties that include a modulus of elasticity up to $40 \mathrm{GPa}$. Moreover, fibers can be further subdivided by hydrolysis followed by mechanical disintegration into microfibrils with an elastic modulus up to $70 \mathrm{GPa}$. Such fibers are produced commercially by the pulp and paper industry [10].

With the exception of cotton, the main components of natural fibers are cellulose, hemicellulose and lignin, and, in minor concentration pectin, waxes and water soluble substances [10]. Linear cellulose molecules are linked laterally by hydrogen bonds to form linear bundles, giving rise to a crystalline structure. The degree of crystallinity of cellulose is one of the most important structural parameters; the rigidity of cellulose fibers increases, but flexibility decreases with increasing ratio of crystalline to amorphous regions. Therefore, the crystalline structure of cellulose is one important parameter for evaluating the physical and mechanical properties [11, 12].

The use of gamma radiation as a mechanism for reaction initiation and accelerator of the polymerization of a monomer in a ceramic matrix can bring considerable advantages. One of the most important objectives is to obtain higher adhesion between fibers and the matrix [13-18]. The first investigations focused on the influence of gamma radiation on lignocellulose materials, in terms of increasing the solubility of insoluble high-polymerized sugars such as cellulose [19]. Some investigations focused on effects of gamma radiation on physicochemical properties of cellulose, and the results show that an increment of $25 \mathrm{kGy}$ (in average) caused a loss of $1 \%$ in cellulose crystallinity in the dose range of 0 $1 \mathrm{MGy}$. Cellulose shows degradation (from 6 to $12 \%$ ) up to $31.6 \mathrm{kGy}$ and unchanged degree of crystallinity up to $300 \mathrm{kGy}$. The degree of polymerization (DP) is obtained up to $1 \mathrm{~Gy}$; this decrease is above $10 \mathrm{kGy}$. Moreover, changes on specific gravity and in the lattice constant are observed up to $1 \mathrm{MGy}$, as well as complete degradation of cellulose at 6.55 MGy. In the case of lignin no changes are observed up to $31.6 \mathrm{kGy}$ and only $15 \%$ of degradation at 19 MGy is observed [19].

In cellulose there is amorphous zones along the microfibril length, in which the crystallinity is interrupted. These zones allow the penetration of chemicals into the microfibrils. Furthermore, the gamma radiation caused break-up of cellulose to shorter chains, which are water-soluble, and it most likely leads to an "opening of additional microcracks," in which water molecules can easily penetrate.
Some studies covering the effects of ionizing radiation on polymer-ceramic composite materials, for example, in gypsum/poly(methyl) acrylate composites showed that the yield of polymerization increased with increasing radiation dose and leveled off at a dose around 3-4 kGy, where a yield of $87-88 \%$ is achieved [9]. As this process is completed at room temperature, there is much economy of heat energy, besides the reduction in costs to keep the composite under pressure. The pressure is used to keep much of the monomer (usually with a high volatility) filling the interstices of the ceramic matrix during the conversion to ceramic-polymer composites.

The purpose of this work was to evaluate gamma radiation and waste cellulose as tools for improvement of mechanical properties of cement concrete. Waste cellulose was obtained from Tetra Pak packages and the gamma doses were covered up to $300 \mathrm{kGy}$. A simple and inexpensive process was expected as well as contribution on the environmental care.

\section{Experimental Part}

2.1. Specimen Preparation. Before preparing concrete specimens, one set of waste cellulose particles with average size of $0.5 \mathrm{~mm}$ was obtained from Tetra Pak packages and was used in concentrations of 3,5, and $7 \%$ by weight; these values were selected in order to avoid problems concerning homogeneity and workability.

Different mixes were elaborated with Portland cement, silica sand, gravel, and water. The sand with uniform granulometry had an average diameter of $150 \mu \mathrm{m}$ (mesh 60), while sizes of gravel were $0.5,4.0$, and $6.3 \mathrm{~mm}$ (mesh 35, 5, and $0.25^{\prime \prime}$, resp.). Proportion of components in the mixes was $1 / 2.75$ for cement/aggregates, with water/cement ratio of 0.485 . All materials were mixed according to practice ASTM C-305. Sand silica was obtained from a local company (GOSA, Atizapan, Mexico), and gravel aggregates were obtained from Tula Hidalgo México, respectively.

After mixing, concrete cylindrical specimens (2.0" diameter and $4.0^{\prime \prime}$ long) were molded. After 24 hours, they were placed in a controlled temperature room (at $23.0 \pm 2.0^{\circ} \mathrm{C}$ and $95 \%$ of relative humidity according to ASTM C/192 M00 ), with the surface exposed to moisture. The moist room conditions were the same as above, according to ASTMC-511. It is important to remark that waste cellulose was used as sand replacement.

2.2. Mechanical Tests. Compressive strength evaluation of all concrete cylindrical specimens was carried out in a universal testing machine model 70-S17C2 (Controls, Cernusco, Italy), according to ASTM C-39M-01, located at Laboratory of Research and Development of Advanced Materials (LIDMA) of the Autonomous University of the State of Mexico (UAEM). Specimens were tested after 7, 14, and 28 days of moist curing. Testing tolerance allowed for the specimens was 7 days \pm 6 hrs, 14 days \pm 9 hrs, and 28 days \pm 12 hrs.

2.3. Irradiation Procedure. The concrete cylindrical specimens were irradiated at 200, 250, and $300 \mathrm{kGy}$ using a ${ }^{60} \mathrm{Co}$ 


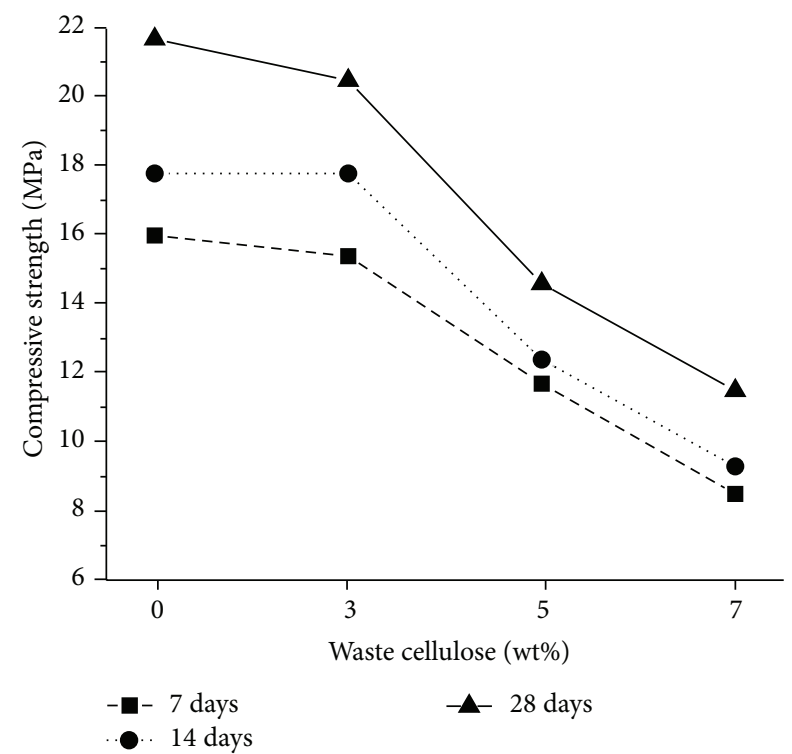

FIGURE 1: Compressive strength of concrete with waste cellulose.

source at the dose rate of $3.5 \mathrm{kGy} / \mathrm{h}$; the experiments were made in air at room temperature. The irradiation was provided by a 651 PT Gammabeam Irradiator manufactured by NORDION (Chalk River, Ontario) and located at Institute of Nuclear Sciences of the National Autonomous University of Mexico.

2.4. Morphological Characterization. The surfaces of irradiated cellulose and those for fractured zones of concrete were analyzed, by a scanning electron microscopy (SEM) in a JEOL model JSM-5200 machine, in the secondary electron mode.

\section{Results and Discussion}

3.1. Compressive Strength. In Figure 1 compressive strength values of concrete with waste cellulose are shown. Concrete without waste cellulose at 28 days of curing time has the highest compressive strength value, namely, 21.7 MPa. Some behaviors are observed. (a) The values gradually decrease when more cellulose is added; (b) concrete with $3 \mathrm{wt} \%$ of waste cellulose has a minimal difference, $5 \%$, with respect to control concrete (without cellulose); it does not happen for concrete with $7 \mathrm{wt} \%$ of waste cellulose, because it has $47 \%$ of reduction; and (c) independently of each cellulose percentage the compressive strength values increase when increasing curing time.

Such reductions in the values can be explained in terms of the waste cellulose added. The strength depends on the amount of waste cellulose and water cement ratio (w/c). By one hand cellulose has a hydrophobic nature and on the other hand the cellulose can substitute up to $7 \mathrm{wt} \%$ of sand in the mixture; thus more amount of water is available to interact into the surface of unhydrated grains of cement particles. Therefore, weak interfacial adhesion between cellulose and

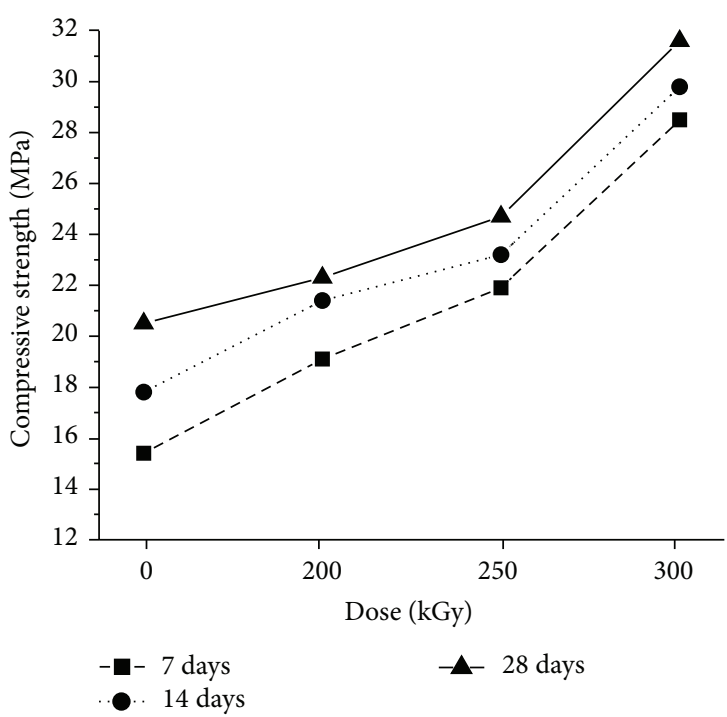

FIGURE 2: Compressive strength of concrete with waste cellulose at different irradiation doses.

hydrated cement particles is obtained; in consequence reduction on the compressive strength values is seen.

According to the highest compressive strength results for concrete with cellulose (seen previously in Figure 1), we decided to work with concrete with $3 \mathrm{wt} \%$ of waste cellulose in the second stage of this study, consisting on irradiating them up to $300 \mathrm{kGy}$. Some behaviors are shown in Figure 2. (a) The highest value is observed for concrete irradiated at $300 \mathrm{kGy}$ at 28 days of curing time, namely, $31.6 \mathrm{MPa}$, which means an improvement of $45 \%$ with respect to control concrete; (b) the values increase when radiation dose increases too; (c) for each gamma dose the values increase when increasing curing time.

Such improvements of the compressive strength values can be explained in terms of the gamma radiation effects on the concrete components and waste cellulose. As we know, many types of chemical reactions take place during gamma irradiation of polymeric materials, cross-linking, and degradation by chain scission among others, but one or the other of these effects may be predominant in some materials. In the present investigation we argue the formation of cross-linking of the polymeric chains in the cellulose under the effect of irradiation dose and their repercussion on the cement and water molecules. We recall that cross-linking is the most important effect of polymer irradiation because it can usually improve the mechanical, thermal, and chemical properties. Moreover, application of high energy irradiation to cellulose creates free radicals by the scission of the weakest bonds; such radicals can react with some molecules in the cement matrix. The interaction between calcium silicate hydrate (formed during the hydration process) and the cellulose present in the pores during irradiation polymerization enhanced the interphase bonding and as a result, an improvement of the mechanical strength takes place.

3.2. Compressive Strain at Yield Point. Similar behavior for compressive strain is observed: (a) the values decrease when 


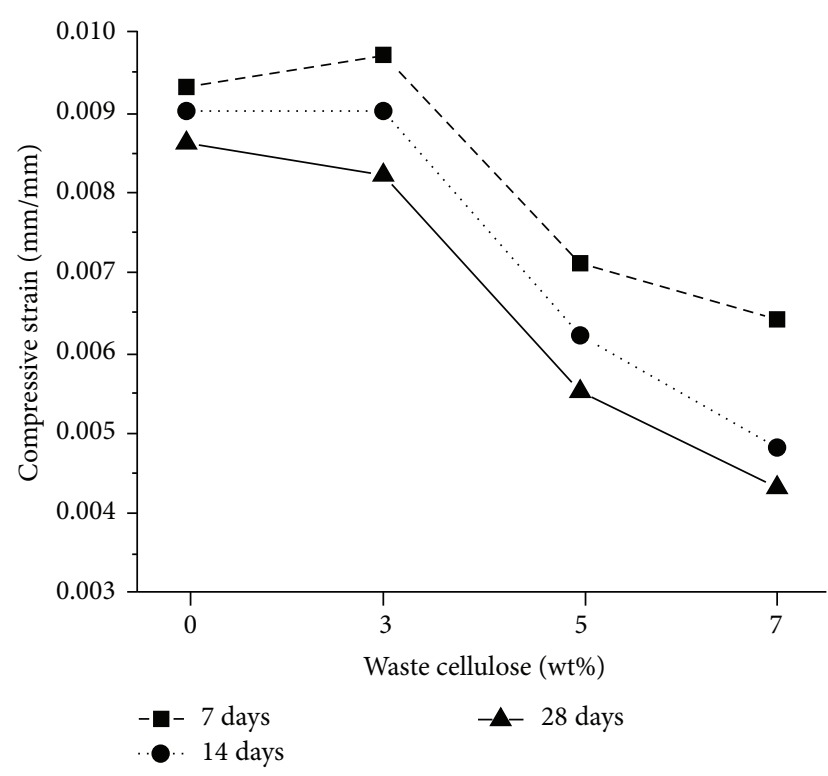

Figure 3: Compressive strain of concrete with waste cellulose.

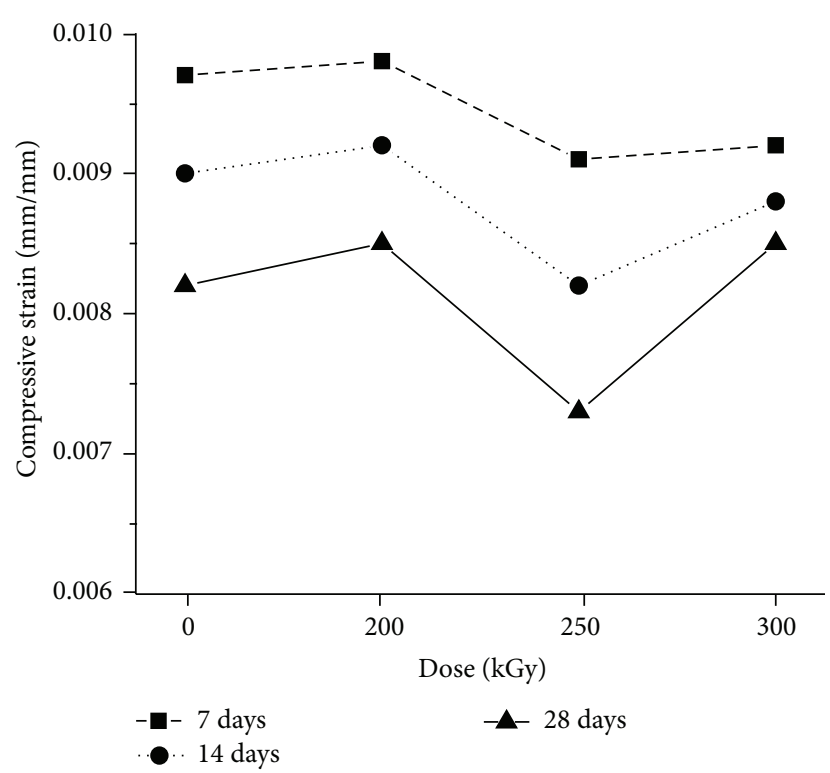

FIGURE 4: Compressive strain of concrete with waste cellulose at different irradiation doses.

more waste cellulose concentration is added; (b) for each waste concentration, the values decrease according to curing time (Figure 3). The lowest value, $0.0043 \mathrm{~mm} / \mathrm{mm}$, is $116 \%$ minor with respect to compressive strain value of control concrete (without waste cellulose). Thus a hard concrete is produced when adding higher waste cellulose concentration.

For irradiated concrete a well-defined behavior is observed (Figure 4). The values show three stages: (a) in the first one the values increase at $200 \mathrm{kGy}$, (b) after they decrease at $250 \mathrm{kGy}$, and finally (c) they increase again at $300 \mathrm{kGy}$. The diminution at $250 \mathrm{kGy}$ is $12 \%$ minor than those for control concrete.

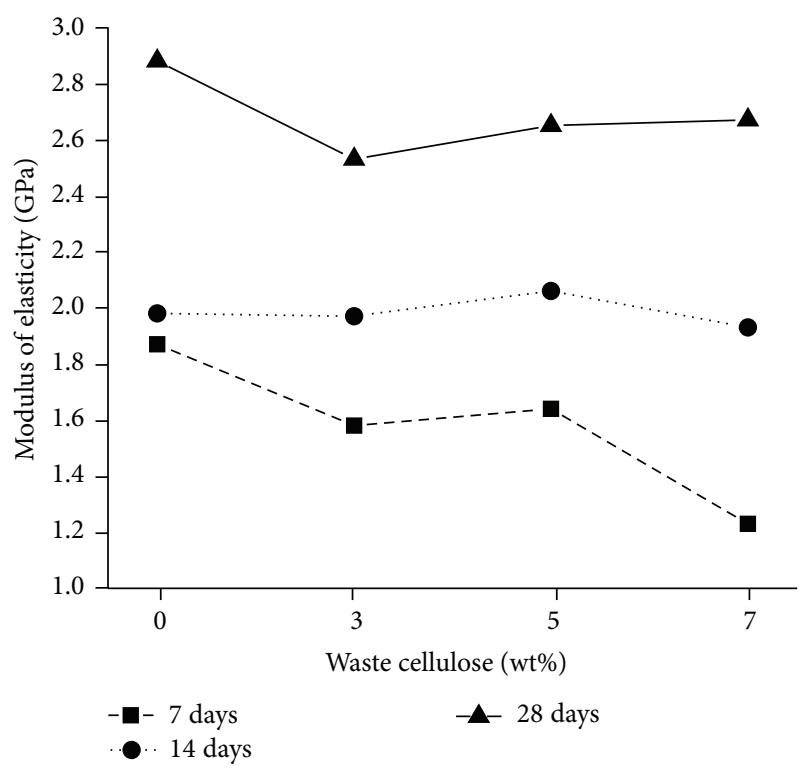

FIGURE 5: Modulus of elasticity of concrete with waste cellulose.

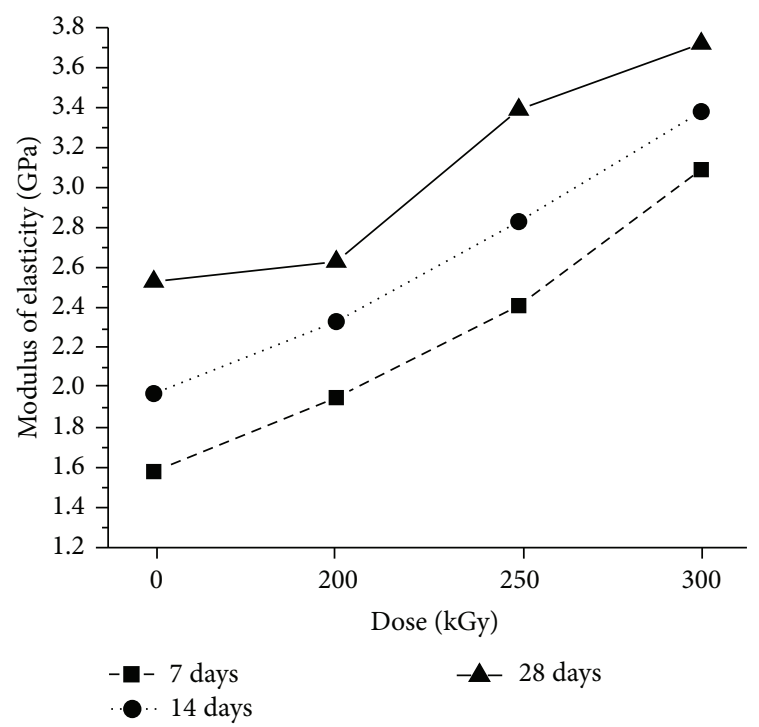

FIGURE 6: Modulus of elasticity of concrete with waste cellulose at different irradiation doses.

3.3. Modulus of Elasticity. The moduli of elasticity values for concrete are shown in Figure 5. Depending on both parameters, waste cellulose concentration and curing time, different behaviors are observed. (a) For concrete with 7 days of curing time the values decrease according to the increase of waste cellulose too, being $35 \%$ minor when adding $7 \mathrm{wt} \%$ of waste cellulose; (b) for concrete with 14 days of curing time, the values are almost constant for any waste cellulose concentration; (c) for concrete with 28 days of curing time, the values diminish at $3 \mathrm{wt} \%$ of waste cellulose, and after increasing up to $7 \mathrm{wt} \%$ of waste cellulose, at this concentration the value is minor with respect to control 

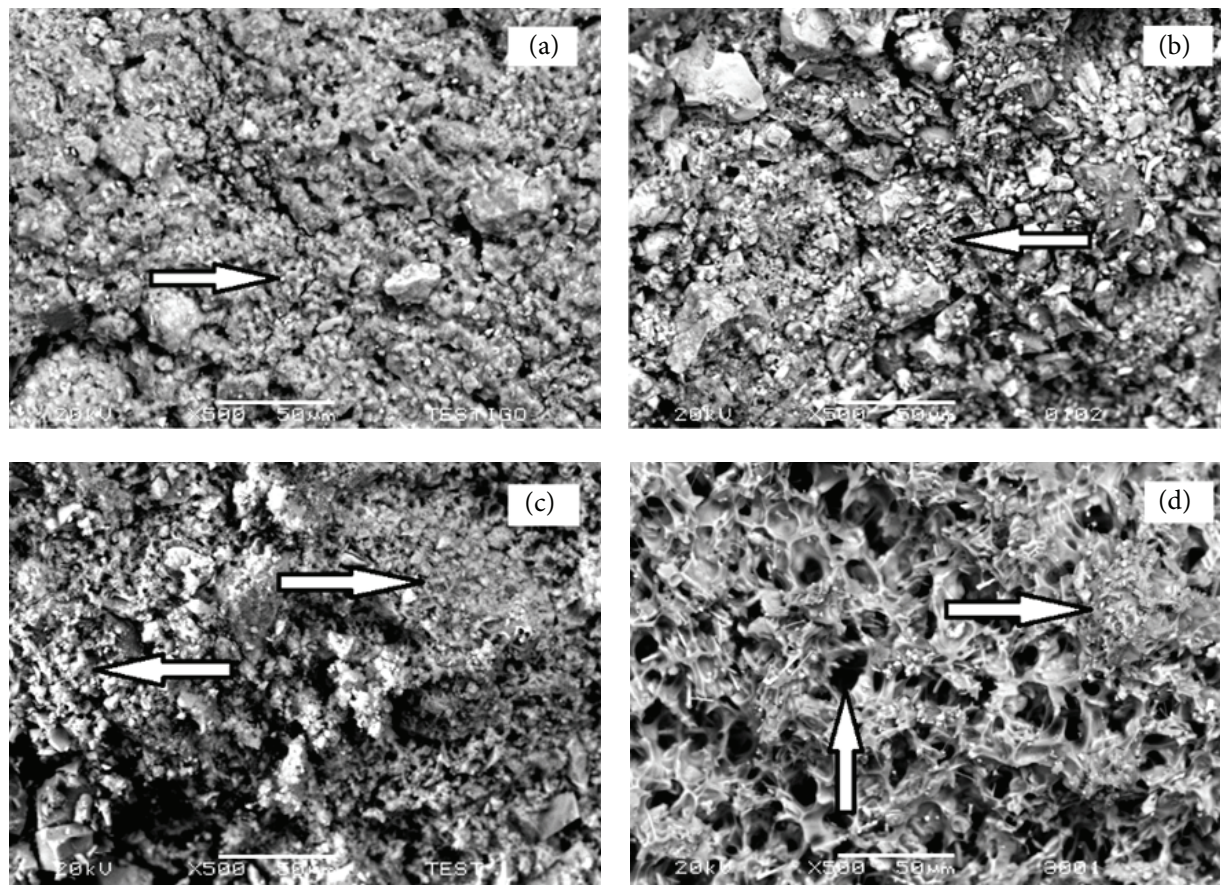

FIGURE 7: SEM images of fractured concrete: (a) nonirradiated; irradiated at (b) $200 \mathrm{kGy}$, (c) $250 \mathrm{kGy}$, and (d) $300 \mathrm{kGy}$.
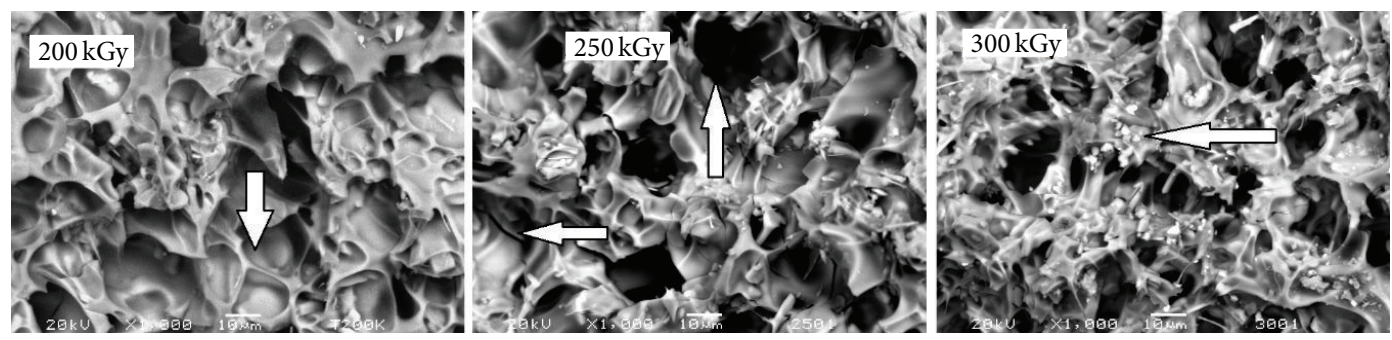

Figure 8: SEM images of irradiated cellulose at $200 \mathrm{kGy}, 250 \mathrm{kGy}$, and $300 \mathrm{kGy}$.

concrete; and (d) for each waste cellulose concentration the values increase according to curing time increase.

In the case of irradiated concrete different behaviors are observed. (a) The values increase according to waste cellulose concentration increase. The highest value is observed for concrete with 28 days of curing time and irradiated at $300 \mathrm{kGy}$, which is $47 \%$ higher with respect to control concrete; (b) for each radiation dose the values increase according to curing time increasing (Figure 6). These results can be attributed to gamma irradiation effects on the waste cellulose. Improvement on modulus of elasticity values point out a predominant domain of cross-linking of polymer chains in cellulose. However, some shorter chains are produced which are water-soluble and in consequence increment on the solubility is done. In general terms, irradiated cellulose covers the sand particles; thus zone around them is affected by a stress concentration. Therefore, if the distance between particles is small enough, these zones join together and form a percolation network, which generate good adhesion between cement matrix and cellulose and in consequence increment in the modulus of elasticity is obtained.
The mechanical results can be related with morphological changes seen on the fractured zones of concrete specimens, as we see in Figure 7. For nonirradiated concrete a rough surface is shown (indicated by arrows) (Figure 7(a)); when applying $200 \mathrm{kGy}$ of dose, the disperse particles are covered by irradiated cellulose (see arrow), as consequence of the cross-links of the polymer chains (Figure 7(b)). For higher dose, $250 \mathrm{kGy}$, the cellulose continues to form polymer films over the hydrating cement particles and thus interferes with the hydration process and thereby setting and hardening of cement (Figure 7(c)); finally at $300 \mathrm{kGy}$ more evident is the presence of cellulose, through the cross-linked regions accompanied with larger quantities of voids in the interfacial zone (see arrows). Nevertheless strong bonds are progressively developed between cellulose and cement matrix (Figure 7(d)).

Figure 8 shows images of irradiated recycled cellulose obtained by Scanning Electron Microscopy (SEM). For irradiated cellulose at $200 \mathrm{kGy}$ smooth and homogeneous surfaces (indicated by arrow) and some particles are seen. When increasing the radiation dose, at $250 \mathrm{kGy}$, some cracks 
and more space between cellulose surfaces appear, giving an appearance of voids. Such modifications can be related with the main effects produced by gamma radiation: scission and cross-linking of molecular chains in cellulose. For higher dose, at $300 \mathrm{kGy}$, a higher number of dispersed particles, as well as rough surfaces, are observed.

\section{Conclusions}

Both waste cellulose concentration and gamma radiation are adequate tools for improvement of the mechanical properties of concrete, where sand is substituted by waste cellulose. In particular, compressive strength and modulus of elasticity values have an improvement of $45 \%$ and $47 \%$, respectively, when adding $3 \mathrm{wt} \%$ of waste cellulose and applying $300 \mathrm{kGy}$ of dose. Conversely, diminutions on the mechanical properties were seen for nonirradiated concrete. Through SEM images the influence of gamma radiation on waste cellulose and its effect on the mechanical properties of concrete was corroborated.

\section{Conflict of Interests}

The authors declare that none of them has a direct financial relationship with the commercial trademarks mentioned in this paper that might lead to a conflict of interests for any of the authors.

\section{Acknowledgment}

Financial support of the Autonomous University of the State of Mexico (UAEM), Toluca, by Grant UAEM 3408/2013M (Megaproyecto) is acknowledged.

\section{References}

[1] C. Meyer, "Recycled materials in concrete," in Developments in the Formulation and Reinforcement of Concrete, S. Mindess, Ed., pp. 208-230, Woodhead Publishing, Cambridge, UK, 2009.

[2] C. Meyer, "The economics of recycling in the US construction industry," in Sustainable Construction Materials and Technologies, Y.-M. Chun, P. Claisse, T. R. Naik, and E. Ganjian, Eds., pp. 509-513, Taylor \& Francis, London, UK, 2007.

[3] C. Barrera-Díaz, V. Varela-Guerrero, E. Cuevas-Yáñez, G. Martínez-Barrera, G. Roa-Morales, and M. A. García-Morales, "Use of recycled aluminum-polyethylene composite films as anodic electrodes for electrocoagulation of wastewater," International Journal of Electrochemical Science, vol. 9, no. 3, pp. 1034-1043, 2014.

[4] M. Bentchikou, A. Guidoum, K. Scrivener, K. Silhadi, and S. Hanini, "Effect of recycled cellulose fibres on the properties of lightweight cement composite matrix," Construction and Building Materials, vol. 34, pp. 451-456, 2012.

[5] A. Murathan, A. S. Murathan, M. Gürü, and M. Balbaşi, "Manufacturing low density boards from waste cardboards containing aluminium," Materials and Design, vol. 28, no. 7, pp. 2215-2217, 2007.

[6] Z. N. Kalantar, M. R. Karim, and A. Mahrez, "A review of using waste and virgin polymer in pavement," Construction and Building Materials, vol. 33, pp. 55-62, 2012.
[7] A. Korkmaz, J. Yanik, M. Brebu, and C. Vasile, "Pyrolysis of the tetra pak," Waste Management, vol. 29, no. 11, pp. 2836-2841, 2009.

[8] H. Fujiwara, M. Maruoka, K. Koibuchi, and K. Fujita, "The application of paper sludge ash to extremely stiff consistency concrete product," in Sustainable Construction Materials and Technologies, Y.-M. Chun, P. Claisse, T. R. Naik, and E. Ganjian, Eds., pp. 303-311, Taylor \& Francis, London, UK, 2007.

[9] M. H. P. Gazineu, V. A. D. Santos, C. A. Hazin, W. E. D. Vasconcelos, and C. C. Dantas, "Production of polymer-plaster composite by gamma irradiation," Progress in Nuclear Energy, vol. 53, no. 8, pp. 1140-1144, 2011.

[10] A. K. Bledzki and J. Gassan, "Composites reinforced with cellulose based fibres," Progress in Polymer Science, vol. 24, no. 2, pp. 221-274, 1999.

[11] M. Åkerholm, B. Hinterstoisser, and L. Salmén, "Characterization of the crystalline structure of cellulose using static and dynamic FT-IR spectroscopy," Carbohydrate Research, vol. 339, no. 3, pp. 569-578, 2004.

[12] E. Gümüskaya, M. Usta, and H. Kirci, "The effects of various pulping conditions on crystalline structure of cellulose in cotton linters," Polymer Degradation and Stability, vol. 81, no. 3, pp. 559-564, 2003.

[13] G. Martínez-Barrera, C. Menchaca Campos, and F. UreñaNuñez, "Gamma radiation as a novel technology for development of new generation concrete," in Gamma Radiation, F. Adrovic, Ed., pp. 91-114, InTech, Rijeka, Croatia, 2012.

[14] L. I. Avila-Córdoba, G. Martínez-Barrera, F. Ureña-Nuñez, and C. E. Barrera-Díaz, "Electron microscopy for the evaluation of concrete surfaces modified by gamma radiation," in Current Microscopy Contributions to Advances in Science and Technology, A. Méndez-Vilas, Ed., pp. 1115-1122, Formatex Research Center, Badajoz, Spain, 2012.

[15] G. Martínez-Barrera and W. Brostow, "Fiber-reinforced polymer concrete: property improvement by gamma irradiation," in Gamma Radiation Effects on Polymeric Materials and Its Applications, C. Barrera-Díaz and G. Martínez-Barrera, Eds., pp. 27-44, Research Signpost, Kerala, India, 2009.

[16] G. Martínez-Barrera, C. Menchaca-Campos, C. E. BarreraDíaz, and L. I. Avila-Cordoba, "Recent developments in polymer recycling," in Gamma Rays: Technology, Applications and Health Implications, I. Bikit, Ed., pp. 237-256, Nova Science Publishers, Hauppauge, NY, USA, 2013.

[17] N. A. El-Faramawy and F. I. El-Hosiny, "The effect of the autoclaving process and addition of silica fume on portland cement in shielding gamma radiation," Radiation Measurements, vol. 29, no. 6, pp. 619-623, 1998.

[18] M. Patel, P. R. Morrell, J. J. Murphy, A. Skinner, and R. S. Maxwell, "Gamma radiation induced effects on silica and on silica-polymer interfacial interactions in filled polysiloxane rubber," Polymer Degradation and Stability, vol. 91, no. 2, pp. 406-413, 2006.

[19] R. Despot, M. Hasan, A. O. Rapp et al., "Changes in selected properties of wood caused by gamma radiation," in Gamma Radiation, F. Adrovic, Ed., pp. 281-304, InTech, Rijeka, Croatia, 2012. 

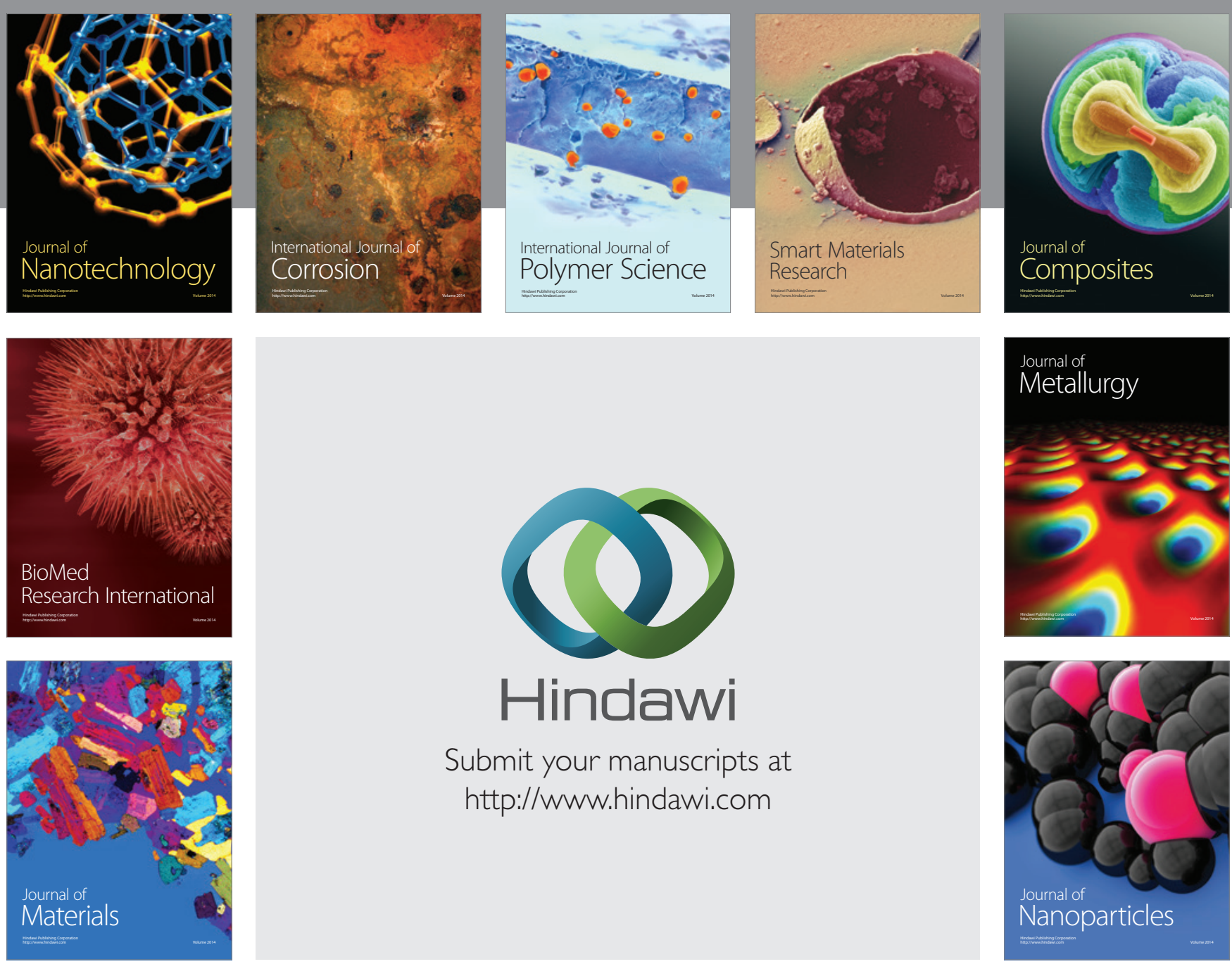

Submit your manuscripts at http://www.hindawi.com
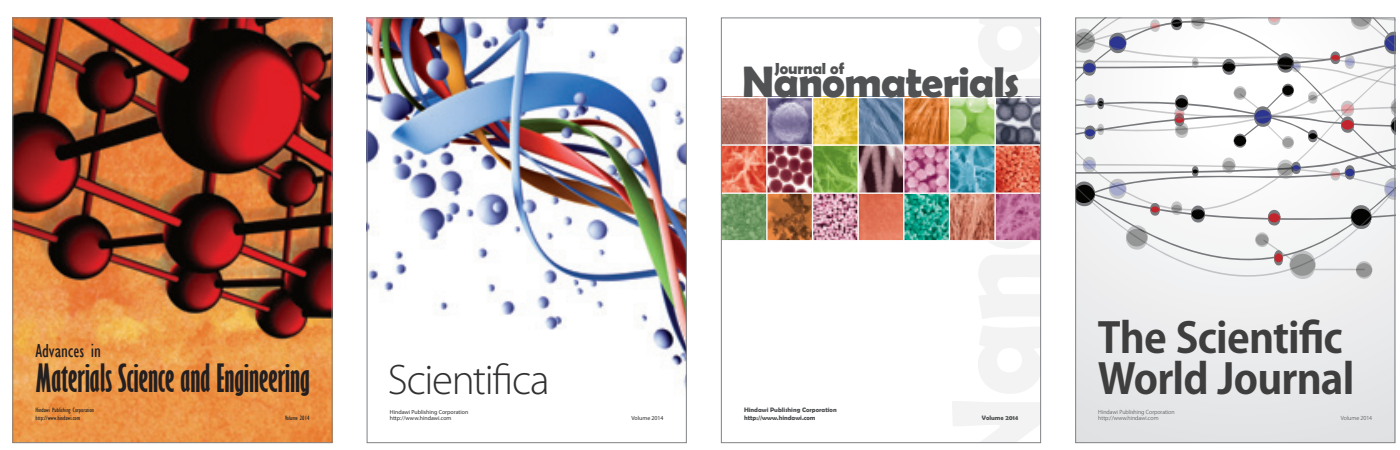

\section{The Scientific World Journal}
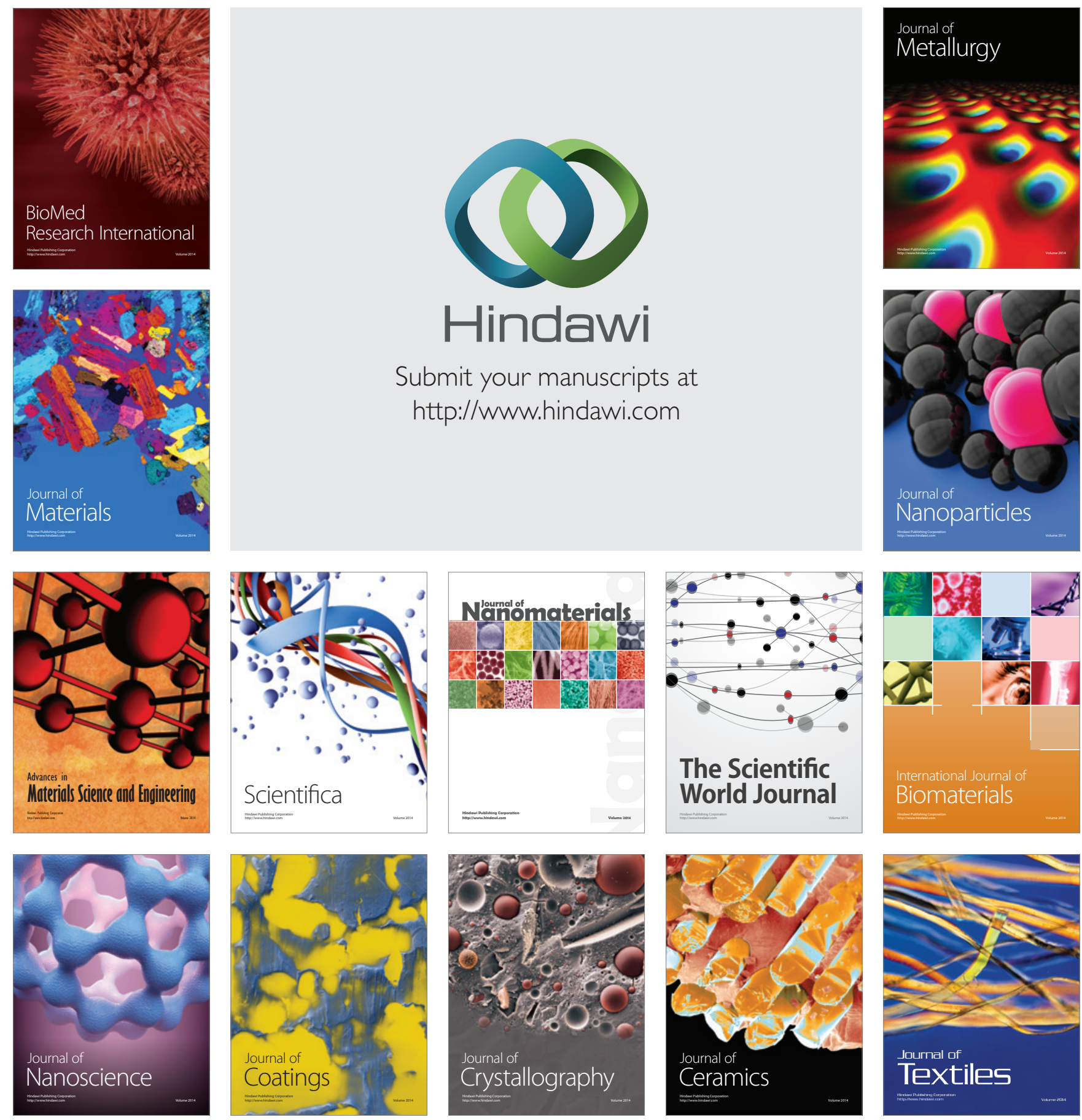